\title{
EFFECT OF MARKET ORIENTATION, ORIENTATION OF TECHNOLOGY AND INNOVATION OF PRODUCTS TO THE ADVANTAGES OF COMPETITIVE PIZZA HUT A.YANI PADANG
}

\author{
Leony Patriona Jonson, Maria Magdalena \\ STIE “KBP” Padang \\ leonypatriona@gmail.com
}

\begin{abstract}
ABTRACT
This research is meant to find out to test the influence of market orientation, technological orientation and product innovation on the competitiveness of Pizza Hut A.Yani Padang. Sample used in this research is Consumer Pizza Hut A.Yani Padang who visited with the status of Dine In (eating restaurant) using the method of Sampling Insidential with the samples of 100 respondents. Data analysis using SPSS software with Linear Regression Analysis. Independent variables in this study are Market Orientation, Technology Orientation, Product Innovation and dependent variable is Competitive Advantage. The result shows Market Orientation has a significant effect on Competitive Advantage. Technological Orientation has a significant effect on Competitive Advantage. Product Innovation has a significant effect on Competitive Advantage.
\end{abstract}

Keywords: Market, Technology, Product, Competitive Advantage.

\section{PENDAHULUAN}

Situasi persaingan dalam sektor bisnis saat ini sangatlah pesat dalam merebut persaingan pasar konsumen. Pesatnya perkembangan teknologi dapat membawa perubahan dalam kehidupan masyarakat baik gaya hidup, pola pikir, mau pun pola konsumsi pangan. Hal ini dapat dilihat dari konsumsi masyarakat terhadap makanan cepat saji. Salah satu bisnis yang perkembanganya sangat pesat saat ini adalah bisnis restoran. Persaingan bisnis restoran fast food atau restoran siap saji yang semakin pesat menyebabkan perusahaan harus mampu memenuhi kebutuhan konsumen dan bersaing dalam memasarkan produknya agar dapat diketahui dan dikenal konsumen (Rosyida, 2016). Setiap perusahaan harus mampu untuk selalu mengerti dan memahami hal yang terjadi di pasar dan yang hal di inginkan konsumen, serta perubahan yang ada agar mampu menyaingi kompetitornya.

Perubahan yang dimaksud disini berkaitan tentang bagaimana cara perusahaan memberikan inovasi untuk menjawab hal yang menjadi keinginan konsumen dan dapat 
menyaingi kompetitor. Harapan perusahaan untuk dapat menciptakan produk yang benar-benar baru lain dari produk yang sebelumnya atau melakukan modifikasi dari produk yang sudah ada sebelumnya dengan melakukan inovasi. Konsumen bukan hanya sekedar melihat pada nilai atau kegunaan dari suatu produk yang dibutuhkan, tetapi konsumen juga melihat apakah produk yang dipilih memiliki keuntungan atau keunggulan lebih di bandingkan produk sejenis lain dan fungsi kegunaan konsumsinya.

Dalam jurnal Heri Setiawan

(2012), Narver dan Slater mendefinisikan orientasi pasar merupakan suatu tradisi organisasi yang paling ampuh dalam mencipkatakan perilaku penting untuk membuat keunggulan yang bernilai lebih untuk konsumen serta kinerja dalam bisnis. Dalam orientasi pasar memiliki 3 indikator perilaku yaitu orientasi pelanggan, orientasi pesaing dan koordinasi interfungsional.

Majunya teknologi saat zaman sekarang ini, menunutut akan kebutuhan informasi yang cepat dan akurat sangatlah diperlukan di segala bidang terutama di bidang bisnis, yang membuat teknologi semakin berkembang dalam mengembangkan suatu produk disebut dengan orientasi teknologi. Orientasi teknologi mampu menciptakan pesaingan yang kuat pada kompetitornya dalam pengembangan produk.

Menurut Ginanjar Suendro (2010) Inovasi produk merupakan cara meningkatkan nilai sebagai sebuah komponen kunci kesuksesan sebuah operasi bisnis yang menjadikan perusahaan mempunyai keunggulan bersaing sebagai pempin pasar.

Menurut Kotler (2010), Keunggulan bersaing merupakan keunggulan melebihi pesaing yang dimiliki perusahaan dan diperoleh dengan menawarkan nilai keuntungan yang lebih tinggi bagi konsumen dibandingkan pesaing. Memahami pesaing sekaligus pelanggan sangatlah penting bagi perusahaan dalam melalui analisis untuk mencapai keunggulan bersaing tersebut. Indikator dalam keunggulan bersaing produk adalah keunikan produk, kualitas produk dan hara bersaing.

Dalam penelitian ini, yang akan dibahas adalah Pengaruh Orientasi Pasar, Orientasi Teknologi dan Inovasi Produk Terhadap Keunggulan Bersaing Pada Pizza Hut A.Yani Padang. Dipilihnya bisnis restoran PIZZA HUT dalam penelitian ini. Dikarenakan banyaknya cabang PIZZA HUT di kota-kota besar di Indonesia dan PIZZA HUT sangat disukai oleh semua kalangan masyarakat di Indonesia. Di Kota Padang Sumatera Barat, restoran Pizza Hut juga berhasil memperoleh perhatian dari kosumen khususnya Pizza Hut A.Yani Padang.

Ada pun tujuan diadakan penelitian ini yaitu Menguji dan menganalisis Pengaruh Orientasi Pasar, Orientasi Teknologi dan 
Inovasi Produk Terhadap Keunggulan Bersaing Pizza Hut A.yani Padang.

\section{TINJAUAN PUSTAKA}

\section{Keunggulan Bersaing}

\section{Pengertian Keunggulan Bersaing}

Kotler dan Armstrong (2009) mendefinisikan keunggulan bersaing adalah keunggulan yang didapatkan dengan menawarkan nilai lebih kecil ataupun dengan harganya lebih tinggi karena memperoleh manfaat yang lebih besar terhadap pesaing. Keunggulan bersaing (competitive advantage) adalah sebagai jantung kinerja pemasaran dalam mengatasai persaingan. Keunggulan bersaing merupakan strategi dari hasil yang di dapatkan oleh perusahaan yang menjalankan kerjasama untuk menciptakan keunggulan bersaing dalam pasarnya dalam pasar yang lebih efektif dan efisien.

\section{Indikator Keunggulan Bersaing}

Menurut Heri Setiawan (2012), ada tiga indikator yang digunakan untuk mengukur keunggulan bersaing yaitu:

1) Keunikan produk

2) Kualitas produk

3) Harga bersaing

\section{Orientasi Pasar}

\section{Pengetian Orientasi Pasar}

Orientasi pasar merupakan sesuatu yang penting bagi perusahaan sejalan dengan meningkatnya persaingan global dan perubahan dalam kebutuhan pelanggan dimana perusahaan menyadari bahwa mereka harus selalu dekat dengan pasarnya. Di dalam jurnal Heri Setiawan (2012), Naver dan Slater mendefinisikan orientasi pasar merupakan suatu tradisi organisasi yang paling ampuh dalam mencipkatakan perilaku penting untuk membuat keunggulan yang bernilai lebih untuk konsumen serta kinerja dalam bisnis.

\section{Indikator Orientasi Pasar}

Menurut Heri Setiawan (2012), orientasi pasar memiliki tiga komponen perilaku yaitu:

1) Orientasi pelanggan

2) Orientasi pesaing

3) Koordinasi intarfungsional.

\section{Orientasi Teknologi}

\section{Pengertian Orientasi Teknologi}

Orientasi teknologi merupakan suatu alat yang digunakan untuk strategi dengan kebijakan pengembangan produk dengan berorientasi teknologi dapat digunakan untuk mangatur persaingan, dengan asumsi bahwa semakin tinggi teknologi yang digunakan akan semakin inovatif produk yang dihasilkan dan semakin besar kemungkinan untuk target menawarkan produk atau jasanya. Pada perusahaan yang berorientasikan pada teknologi dapat diartikan bahwa perusahaan dapat menggunakan pengetahuan teknisnya guna membuat solusi teknis dalam menjawab dan terpenuhinya 
kebutuhan penggunanya (Setiawan, 2012).

\section{Indikator Orientasi Teknologi}

Menurut Wahyudiono (2009), ada dua indikator yang digunakan dalam orientasi teknologi yaitu

1) Komitmen terhadap riset pengembangan

2) Akuisisi teknologi.

\section{Inovasi Produk}

\section{Pengertian Inovasi Produk}

Sensi Tribuana Dewi (2006), Inovasi produk merupakan sesuatu yang dapat dilihat sebagai kemajuan fungsional produk yang dapat membawa produk selangkah lebih maju dibandingkan dengan produk pesaing. Apabila produk tersebut memiliki suatu kelebihan yang dipandang sebagai nilai tambah bagi konsumen.

Pengembangan produk baru dan strategisnya yang lebih efektif seringkali menjadi penentu keberhasilan dan kelangsungan hidup suatu perusahaan, tetapi ini bukan pekerjaan yang mudah. Pengembangan produk baru memerlukan upaya, waktu dan kemampuan termasuk besarnya resiko dan biaya kegagalan. Dalam penelitian Sukarmen (2013), mengemukakan 3 (tiga) karakteristik inovasi yaitu keunggulan produk, biaya produk dan kredibilitas produk.

\section{Indikator Inovasi Produk}

Menurut Sensi Tribuana Dewi (2006), Inovasi produk memiliki tiga indikator yaitu:

1) Perluasan lini

2) Produk baru

3) Produk benar-benar baru

\section{Kerangka Konseptual}

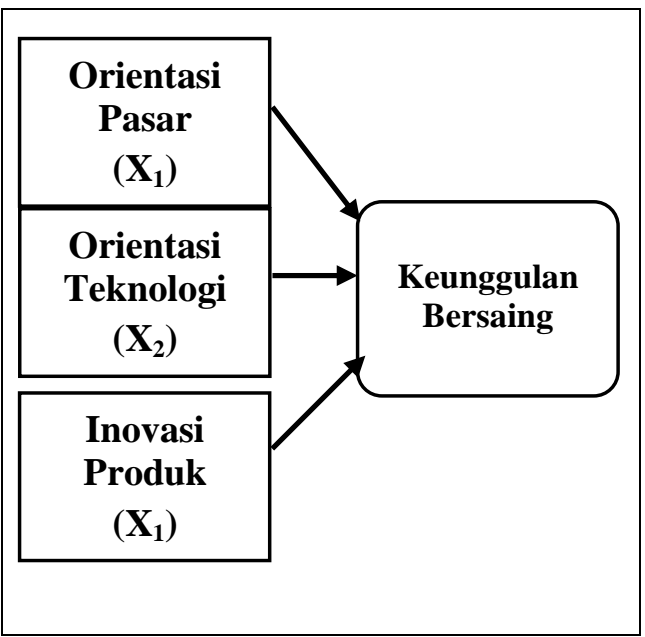

\section{Hipotesis}

Hipotesis yang diajukan dalam penelitian ini adalah :

H1 : Diduga Orientasi Pasar berpengaruh signifikan terhadap Keunggulan Bersaing Pizza Hut A.Yani Padang?

H2 : Diduga Orientasi Teknologi berpengaruh signifikan Terhadap Keunggulan Bersaing Pizza Hut A.Yani Padang?

H3 : Diduga Inovasi Produk berpengaruh signifikan Terhadap Keunggulan Bersaing Pizza Hut A.yani Padang ? 


\section{METODE PENELITIAN}

\section{Jenis Penelitian}

Jenis penelitian ini menggunakan metode kuantitatif, disebut metode kuantitatif karena data penelitian berupa angka-angka dan analisis menggunakan statistik (Sugiyono, 2015). Penelitian kuantitatif mencakup setiap jenis penelitian yang didasarkan atas perhitungan presentase, dan perhitungan statistik lainnya. Dengan kata lain penelitian kuantitatif adalah penelitian yang dapat dinyatakan dengan angka dan dapat dihitung dengan menggunakan rumus-rumus tertentu.

\section{Populasi dan Sampel}

Populasi yang akan diamati dalam penelitian ini adalah Konsumen Pizza Hut A.Yani Padang berjumlah 14.318 orang konsumen yang berkunjung dengan status Dine In (makan direstoran) pada tahun 2017. Berdasarkan perhitungan sample yang diambil dalam penelitian ini menggunakan rumus Slovin sebesar 100 sampel konsumen Pizza Hut A.Yani Padang.

\section{Hasil Penelitian}

\section{Analisa Regresi Linear Berganda}

Persamaan linear berganda untuk Pengaruh Orientasi Pasar, Orientasi Teknologi dan Inovasi Produk terhadap Keunggulan Bersaing Pizza Hut A.Yani Padang adalah sebagai berikut :

$$
\begin{gathered}
\mathrm{Y}=\alpha+\beta_{1} \mathrm{X}_{1}+\beta_{2} \mathrm{X}_{2}+\beta_{3} \mathrm{X}_{3}+\mathrm{e} \\
\mathrm{Y}=2.999+\left(-0,004 \mathrm{X}_{1}\right)+\left(-0,094 \mathrm{X}_{2}\right)+ \\
0,033 \mathrm{X}_{3}+\mathrm{e}
\end{gathered}
$$

\section{Hasil Uji F}

Uji F dilakukan untuk menguji pengaruh variabel bebas secara simultan. Hasil uji F Orientasi Pasar, Orientasi Teknologi dan Inovasi Produk terhadap Keunggulan Bersaing. Dapat diketahui bahwa secara bersama-sama variabel bebas memiliki pengaruh yang positif dan signifikan terhadap variabel terikat. Hal ini dibuktikan dengam nilai $F$ yang dihasilkan dari tabel diatas 0.707 dan nilai signifikan yang bernilai 0.550 lebih besar dari 0,05 menunjukan pengaruh yang diberikan signifikan.

\section{Hasil Uji Parsial (T)}

Uji t dilakukan untuk melihat apakah ada pengaruh yang signifikan atau tidak secara parsial antara orientasi pasar, orientasi teknologi dan inovasi produk terhadap keunggulan bersaing. Adapun hasilnya dapat dilihat sebgai berikut :

1. Uji Hipotesis Orientasi Pasar Ho : Orientasi pasar tidak berpengaruh positif terhadap keunggulan bersaing. Ha : Orientasi pasar berpengaruh positif terhadap keunggulan bersaing.

Berdasarkan hasil pengujian uji $\mathrm{T}$ diatas dapat disiumpulkan bahwa nilai bahwa nilai $\mathrm{T}$ hitung Orientasi Pasar terhadap keunggulan bersaing sebesar (-0.080) dengan 
signifikan $0,937>0,05$. Hal ini berarti nilai signifikan $>0,05$ diterima dan Ho ditolak, artinya Orientasi Pasar berpengaruh positif terhadap Keunggulan Bersaing.

2. Uji Hipotesis Orientasi Teknologi Ho : Orientasi Teknologi tidak berpengaruh positif terhadap Keunggulan Bersaing.

$\mathrm{Ha}$ : Orientasi Teknologi berpengaruh positif terhadap Keunggulan Bersaing.

Berdasarkan hasil pengujian uji $\mathrm{T}$ diatas dapat disimpulkan bahwa nilai $\mathrm{T}$ hitung Orientasi Teknologi terhadap Keunggulan Bersaing sebesar (-1.371) dengan signifikan $0,174>0,05$. Hal ini berarti signifikan > 0,05 diterima dan $\mathrm{Ho}$ ditolak, artinya Orientasi Teknologi berpengruh terhadap Keunggulan Bersaing.

3. Uji Hipotesis Inovasi Produk Ho : Inovasi Produk tidak berpengaruh positif terhadap Keunggulan Bersaing.

Ha : Inovasi Produk berpengaruh positif terhadap Keunggulan Bersaing.

Berdasarkan hasil pengujian uji T diatas dapat disimpulkan bahwa nilai $\mathrm{T}$ hitung Inovasi Produk terhadap Keunggulan Bersaing sebesar 0.587 dengan signifikan $0,559>0,05$. Hal ini berarti T hitung lebih kecil dari signifikan > 0,05 diterima dan Ho ditolak, artinya Inovasi Produk berpengruh terhadap Keunggulan Bersaing.

Uji Koefisien Determinasi $\left(\mathbf{R}^{2}\right)$
Dari hasil pengolahan data koefisien determinasi $\left(\mathrm{R}^{2}\right)$ di atas dapat terlihat pada Adjusted $R$ Square sebesar 0,352 , yang mempunyai arti bahwa variabel keunggulan bersaing (Y) di pengaruhi oleh variabel orientasi pasar (X1), orientasi teknologi (X2) dan inovasi produk (X3) sebesar 35,2\%. Sedangkan sisanya $64,8 \%$ keunggulan bersaing dipengaruhi oleh variabel-variabel lainnya yang tidak diteliti dalam penelitian ini, contohnya variable marketing mix, keputusan pembelian dan potongan harga.

\section{KESIMPULAN DAN SARAN}

\section{Kesimpulan}

Dari hasil pengujian hipotesis yang telah dilakukan mengenai analisis Pengaruh Orientasi Pasar, Orientasi Teknologi dan Inovasi Produk terhadap Keunggulan Bersaing maka dapat ditarik kesimpulan sebagai berikut:

1. Variabel orientasi pasar berpengaruh positif dan signifikan terhadap keunggulan bersaing dengan nilai sig $0.937>0.05$, maka hipotesis diterima karna mendukung hipotesis $1\left(\mathrm{H}_{1}\right)$ bahwa orientasi pasar berpengaruh positif dan signifikan terhadap keunggulan besaing.

2. Variabel orientasi teknologi berpengaruh positif dan signifikan terhadap pengaruh keunggulan besaing dengan nilai sig $0.174>0.05$, maka 
hipotesis diterima karna mendukung hipotesis $2\left(\mathrm{H}_{2}\right)$ bahwa orientasi teknologi berpengaruh terhadap keunggulan bersaing.

3. Variabel inovasi produk berpengaruh positif dan signifikan terhadap pengaruh keunggulan besaing dengan nilai sig $0.559>0.05$, maka hipotesis diterima karna mendukung hipotesis $3\left(\mathrm{H}_{3}\right)$ bahwa inovasi produk berpengaruh terhadap keunggulan bersaing.

\section{UCAPAN TERIMA KASIH}

Dengan selesainya penulisan artikel ini, penulis mengucapkan terima kasih kepada pihak-pihak yang membanti selama proses penulisan.

1. Bapak Febryandhie Ananda, SE, M.Si, selaku Ketua di STIE “KBP” Padang.

2. Ibu Lidya Martha, SE, MM selaku Wakil Ketua di STIE "KBP" Padang.

3. Ibu Febsri Susanti, SEI, MM selaku Ketua Program Studi Manajemen di STIE "KBP" Padang.

4. Ibu Maria Magdalena, S.Pd, MM, selaku Penasehat Akademik Program Studi Manajemen di STIE "KBP" Padang dan sekaligus selaku Dosen Pembimbing Skripsi di STIE “KBP” Padang.
DAFTAR PUSTAKA

Devita, Fransiscus, D., \& Kartini. (n.d.). SISTEM INFORMASI MANAJEMEN PEMASARAN PRODUK PADA, 1-9.

Dewi, S. T. (2006). UNTUK MENINGKATKAN KINERJA PEMASARAN ( Studi pada Industri Batik di Kota dan Kabupaten Pekalongan ).

Fernos, J., \& Putra, Y. E. (2019). Analisa Pengaruh Kualitas Pelayanan Terhadap Kepuasan Nasabah Pada PT. Bank Mega Syari'ah Padang. https://doi.org/10.31219/osf.io/y 2 baf

Ghozali, I. (2011). Aplikasi Analisis Multivariate dengan Program IBM SPSS 20 (6th ed.). Semarang: Universitas Diponegoro.

GINANJAR SUENDRO, S. (2010). Analisis Pengaruh Inovasi Produk Melalui Kinerja Pemasaran Untuk Mencapai Keunggulan Bersaing Berkelanjutan (Studi Kasus Pada Industri Kecil dan Menengah Batik Pekalongan). Jurnal Sains Pemasaran Indonesia, IX(2), 230-243.

Kudus, R. S. (2014). Repositori Stain Kudus, 12(1), 10-41.

Marlius, D. Putriani, I. (2019). Kepuasan Nasabah PT. Bank Rakyat Indonesia Unit Tapan Cabang Painan Dilihat dari Kualitas Layanan Customer Service. Jurnal Pundi. Volume 3. No. 2. Hal.111-122. https://doi.org/10.31575/jp.v3i2 .151

Marlius, D. Ananda, F. (2019). Pengaruh Kualitas Pelayanan Website Akademik Terhadap Minat Kuliah di AKBP Padang. Jurnal Pundi, Vol. 03, No. 03. 
Hal.

191-204.

https://doi.org/10.31575/jp.v3i3 .190

Marlius, D. (2017). Keputusan Pembelian Berdasarkan Faktor Psikologis Dan Bauran Pemasaran Pada PT. Intercom Mobilindo Padang. Jurnal Pundi. Volume 1. No. 1. Hal. 57-66.

https://doi.org/10.31575/jp.v1i1 .9

Marlius, D. (2016). Pengaruh Bauran Pemasaran Jasa Terhadap Minat Nasabah Dalam Menabung Pada Bank Nagari Cabang Muaralabuh.

https://doi.org/10.31227/osf.io/v dqgx

Marlius, D. (2018). Loyalitas Nasabah Bank Nagari Syariah Cabang Bukittinggi Dilihat Dari Kualitas Pelayanan. Jurnal Pundi. Volume 1. No. 3. Hal.12-22.

https://doi.org/10.31575/jp.v1i3 .60

Marlius, D. (2018). Pengaruh Dimensi Kualitas Pelayanan Website Akademik Terhadap Kepuasan Mahasiswa Pada STIE "KBP". Jurnal Ipteks Terapan. Volume 12. No. 2. Hal. 116-128. http://doi.org/10.22216/jit.2018. v12i2.633

Marlius, D. RD Putra. (2018). Strategi Pengembangan Sulam Bayang. Jurnal Benefita: Ekonomi Pembangunan Manajemen Bisnis Dan Akuntansi. Volume 3. No. 2. Hal. 204-218. http://doi.org/10.22216/jbe.v3i2 .3494

Fernandes, Y. D., \& Marlius, D. (2018). Peranan Customer Service Dalam Meningkatkan
Pelayanan Kepada Nasabah Pada PT. Bank Pembangunan Daerah Sumatera Barat Cabang Utama Padang. https://doi.org/10.31227/osf.io/ wrh3p

Meike Supratono. (2009). Strategi Menciptakan Keunggulan Bersaing Produk Melalui Orientasi Pasar, Inovasi, dan Orientasi Kewirausahaan Dalam Rangka Meningkatkan Kinerja Pemasaran.

Nofiawaty, \& Yuliandi, B. (2016). PENGARUH ATMOSFER TOKO, PROMOSI DAN PELAYANAN TERHADAP KEPUTUSAN PEMBELIAN KONSUMEN PADA MATAHARI. Jurnal Ilmu Dan Riset Manajemen, 5(7), 2016.

PRAKOSO, B. (2005). Pengaruh Orientasi Pasar, Inovasi Dan Orientasi Pembelajaran Terhadap Kinerja Perusahaan Untuk Mencapai Keunggulan Bersaing (Studi Empiris Pada Industri Manufaktur Di Semarang). Jurnal Studi Manajemen Dan Organisasi (JSMO), 2(Nomor 1), 35-57. Retrieved from http://eprints.undip.ac.id/15063/ \% 5Cnhttp://eprints.undip.ac.id/ 15063/1/Pengaruh_Orientasi_P asar,_Inovasi....by_Bagas_Prak osa(OK1).pdf

Putra, Y. E., \& Aziz, N. (2019). Pengaruh Kualitas Pelayanan Dan Kepuasan Pelanggan Terhadap Loyalitas Nasabah PT. Bank Rakyat Indonesia Cabang Padang. https://doi.org/10.31219/osf.io/h csw2

Rosyida, A. F. (2016). PENGARUH BAURAN PEMASARAN TERHADAP KEPUTUSAN 
PEMBELIAN, 5.

Setiawan, H. (2012). PENGARUH

ORIENTASI

PASAR,

ORIENTASI TEKNOLOGI

DAN INOVASI PRODUK

TERHADAP KEUNGGULAN

BERSAING

USAHA

SONGKET SKALA KECIL DI

KOTA PALEMBANG Heri

Setiawan, (November), 12-19.

sugiyono. (2015). statistik

nonparametriks untuk

penelitian. bandung: alfabeta.

Sukarmen, P. (2013). Analisis

Pengaruh Inovasi Produk

terhadap Kepuasan Konsumen

dengan Keunggulan Bersaing

Sebagai Variabel Intervening pada Produk Gula Pasir Sebelas (GUPALAS) Pabrik gula

Semboro PTP Nusantara XI (Persero).

Sundalangi, M., Mandey, S. L., Jorie, R. J., Produk, K., Produk, K., Iklan, D. T., ... Terhadap, H. (2014). KUALITAS PRODUK, DAYA TARIK IKLAN, DAN POTONGAN HARGA TERHADAP MINAT BELI KONSUMEN PADA PIZZA HUT MANADO, 2(1), 313324.

Susilawati, C. D. K. (2012). Analisis Perbandingan Pengaruh Likuiditas , Solvabilitas , dan Profitabilitas Terhadap Harga Saham pada Perusahaan LQ 45. Jurnal Akuntansi, 4(2), 165174.

Sutrisni. (2010). Analisis Pengaruh Kualitas Produk, Kualitas Pelayanan, Desain Produk, Harga Dan Kepercayaan.

Voss, G. B., \& Voss, Z. G. (2000). Strategic Orientation and Firm Performance in an Artistic, 64(January), 67-83.

Wahyudiono. (2009a). Pengaruh
Karakteristik

Orientasi

Teknologi Terhadap, (110), 437-455. 